\title{
Sodium intake in Germany estimated from sodium excretion measured in spot urine samples
}

\author{
Stefanie Klenow ${ }^{*}$ D, Michael Thamm and Gert B. M. Mensink
}

\begin{abstract}
Background: Population sodium intake and its impact on public health has been a subject of a critical scientific debate for many years. The German Health Interview and Examination Survey for Adults (DEGS1) facilitate the biomarker-based estimation of sodium intake of the German population, although using spot urine concentrations to extrapolate to daily excretion estimates is associated with uncertainties that should be considered.

Methods: Casual spot urine samples of 6910 German adults collected in DEGS1 were used to representatively estimate sodium intake of the German population. To extrapolate from spot urine concentrations to daily sodium excretion, five published equations were applied, and the results were compared to recommended sodium intake values.

Results: The estimated means range from 166-230 mmol/d (men) and from 124-194 mmol/d (women). The variability of results also differs between applied equations; interquartile ranges vary between 41 and $133 \mathrm{mmol}$ (men) and 21 and $118 \mathrm{mmol}$ (women).

Conclusions: Regardless of the applied equation, most German adults consume much more sodium than recommended by several institutions. To reduce uncertainty and to fully exploit the potential of biomarker-based estimates of sodium intake, either the sampling strategy should be expanded or the extrapolation from spot urines to daily intake should be refined.
\end{abstract}

Keywords: Sodium intake, Sodium excretion, Salt intake, Spot urine, DEGS1

\section{Background}

Sodium intake has been critically and controversially discussed for many years [1]. It has been argued that high sodium intake negatively impacts cardiovascular health due to its potential to elevate blood pressure [2-10]. Sodium intake may have an impact on cardiovascular health independently from its association with blood pressure. For instance, a reduction of sodium intake from $154 \mathrm{mmol} / \mathrm{d}$ to $103 \mathrm{mmol} / \mathrm{d}$ in normotensive overweight and obese subjects improved endothelial function even without affecting blood pressure [11]. Recently, increased sodium tissue storage was detected in hypertensive persons compared to normotensives [12]. Therefore, measurement of sodium in tissues might provide new

\footnotetext{
* Correspondence: Klenows@rki.de; MensinkG@rki.de Department of Epidemiology and Health Monitoring, Robert Koch Institute, Berlin, Germany
}

insight in the relationship between sodium and health in the future. Furthermore, sodium intake has also been associated with other health issues with varying degrees of evidence $[13,14]$.

The World Health Organization (WHO) and other institutions have published recommendations on healthy sodium intake based on the evidence regarding the relationship between sodium intake and blood pressure, allcause mortality, and cardiovascular diseases, among others. The WHO strongly recommends consuming less 85 mmol sodium per day [15], which is equivalen ation (AHA) recommends less than $65 \mathrm{mmol}$ sodium day to improve cardiovascular health of all American [16]. In 2005, the Panel on Dietary Reference Intakes for Electrolytes and Water of the Institute of Medicine (IOM) 
established an adequate intake (AI) for young adults of 65 mmol sodium [17]. The Tolerable Upper Intake Level (UL) was set to $100 \mathrm{mmol}$ sodium per day. Recently, the Committee on Consequences of Sodium Reduction in Populations from the IOM found consistent evidence to still recommend reducing excessive dietary sodium intake. However, they also concluded that the evidence of direct health outcomes of sodium intakes below $100 \mathrm{mmol}$ sodium is inconsistent and insufficient to deduce either risk reduction or enhancement of cardiovascular diseases or all-cause mortality [2]. The European Food Safety Authority (EFSA) did not find in 2005 that the available data were sufficient to establish an UL for sodium from dietary sources [18]. According to the nutrition societies of Germany (DGE), Austria (ÖGE), and Switzerland (SGE), sodium intake of circa $100 \mathrm{mmol}$ is sufficient. Benefits of higher intake are not expected, but disadvantages are likely [19].

There are several methods to measure and monitor sodium intake in populations-all with their inherent strengths and limitations [20-23]. Collection of 24-h urine samples is still the gold standard for assessing sodium intake. However, a large population-based study like DEGS with a broad spectrum of investigations already requires high participant compliance. Collection of 24-h urine samples would increase participant burden and would negatively impact response rate. In addition, the completeness of 24-h urine samples is crucial for this method and requires validation. Logistical effort also makes this sampling method more expensive compared to the collection of spot urine. Furthermore, 24-h urine collection is critically discussed as a proper measure of usual sodium intake because it only reflects the sodium intake of the preceding one or two days and not the usual individual sodium consumption [24]. Monitoring population sodium intake using spot urine samples is a convenient and economical alternative, but, its ability to predict daily sodium intake is controversial [22].

Sodium intake estimates of the German population originate from dietary intake surveys. According to dietary history interviews in the 1998 German Nutrition Survey (median estimates), Germans consume $130 \mathrm{mmol}$ (men) and $96 \mathrm{mmol}$ (women) of sodium daily [25]. In the German National Nutrition Survey II (Nationale Verzehrsstudie II; NVSII), dietary history interviews were applied and median sodium intakes were estimated to be $152 \mathrm{mmol}$ (men) and $113 \mathrm{mmol}$ (women) per day [26, 27]. Recently, Johner et al. [28] estimated median daily sodium intake based on casual spot urines sampled in DEGS to be $171 \mathrm{mmol} \mathrm{(men)} \mathrm{and} 144 \mathrm{mmol}$ (women).

The aim of this study was to estimate nationally representative biomarker-based means and ranges of sodium intake of the German adult population and to assess the proportion of individuals who meet the proposed intake limits as recommended by the WHO. Different methods for extrapolation of concentrations in spot urine to daily sodium excretion were used and compared. This comparison provides insight into the uncertainty that arises from the methods of extrapolation and possible consequences for further studies and public health policies.

\section{Methods}

\section{Study design and subjects}

DEGS1 (German Health Interview and Examination Survey for Adults) is a comprehensive nationwide health survey [29]. The study is representative of the German population aged 18-79 years and was conducted from November 2008 to December 2011. Details on study design and sampling procedures can be found elsewhere [29]. In total, 7987 participants were at the target age of 18-79 years. Among these individuals, 7015 provided casual spot urine samples during their visit at the study center. This could be at any daytime. Of these, 52 participants under medical treatment for renal insufficiency were excluded, and four participants were excluded from the analysis due to creatinine values below the method quantification limit (MQL). Additionally, participants with missing information on body mass or body height were excluded, and one participant was excluded because of a missing potassium concentration in the urine. That information is needed to extrapolate sodium concentrations in spot urine to the daily excreted sodium. Thus, data from 6910 participants were used for the analysis. Anthropometric examinations included a standardized measurement of body mass and body height with participants only wearing underwear. Body mass index (BMI) was calculated from body mass and body height. Socioeconomic status was assigned based on information on education, occupation and income [30].

Sodium and creatinine in casual spot urine were measured by ion-sensitive electrode (ISE), an indirect method, on the Architect platform CI 8200, Abbott, USA (sodium), and using a colorimetric method (picrate), also on the Architect CI 8200, Abbott, USA (creatinine). The MQL was $20 \mathrm{mmol} / \mathrm{L}$ and $0.44 \mathrm{mmol} / \mathrm{L}$ for sodium and creatinine, respectively. The sodium concentration was below MQL in 337 casual spot urine samples. In these instances, the concentration of sodium was assigned to $19 \mathrm{mmol} / \mathrm{L}$ to calculate daily sodium excretion. A sensitivity analysis was performed assuming a sodium concentration of $1 \mathrm{mmol} / \mathrm{L}$ in these cases. The creatinine concentration was below MQL in four casual spot urine samples that were not considered for further calculations.

\section{Urine analysis}

Five equations to estimate sodium excretion within $24 \mathrm{~h}$ from spot urine concentrations of sodium and creatinine 
were identified from literature $[28,31-36]$ and applied to the dataset. Table 1 provides key information on the study populations that have been used to derive the equations. All equations use creatinine to extrapolate spot concentrations to 24-h quantities. Four equations estimated creatinine reference values for this purpose $[28,31-34,36]$. The creatinine reference value is the predicted daily creatinine excretion that depends mainly on muscle metabolism and is fairly constant within a person. All considered age to estimate the creatinine reference value $[28,31-34,36]$ and three equations considered sex [28, 31, 33, 34, 36] and body mass/body height [31-34] (Table 1). Daily sodium excretion is estimated based on concentrations of sodium and creatinine in spot urine specimen and creatinine reference values in four equations [28, 31-33]. One equation also included sex [31]. The equation published by Brown et al. [35] did not estimate creatinine reference values but considered parameters including sex, BMI, and age in the equation for daily sodium estimation (Table 1).

\section{Statistical analyses}

All analyses were performed with SAS (version 9.4; SAS Institute Inc., Cary, NC, USA). A weighting factor was used which adjusts for various sampling probabilities within the design strata and corrects deviations in the sample from the German population structure (as of December 31, 2010) to obtain results that are representative of the German population. The weighting factor takes into account age, sex, region, and nationality, community type and education. Calculation of the weighting factor also considered re-participation probability of GNHIES98 (German National Health Interview and Examination Survey 1998) participants [29, 37]. Intraclass correlation coefficients (ICC) were calculated using SPSS (version 21.0.0.0; IBM SPSS Statistics) because SPSS provides a subcommand to easily estimate ICC, which is a measure of correlation of the results obtained with the various equations.

\section{Results}

\section{Study population}

Basic characteristics of the DEGS1 study population are presented in Table 2.

\section{Estimates of daily sodium excretion}

Mean daily sodium excretion estimated with these equations ranges between 166 and $230 \mathrm{mmol}$ in men and 124 and $194 \mathrm{mmol}$ in women (Table 3). Median daily sodium excretion ranges from $164-228 \mathrm{mmol}$ in men and from 123-190 mmol in women (Table 3).

Among men, the lowest sodium excretion was estimated with Brown's and Tanaka's equation and among women with Brown's and Toft's equation. The highest estimates result from Kawasaki's equation (both sexes). Almost all equations resulted in approximately 15-30 \% lower mean sodium estimates for women $(p<0.0001)$ except Tanaka's equation because sex is not considered in the calculation. However, because body mass and height were included, estimated daily sodium excretion with Tanaka's equation also resulted in $5 \%$ lower estimates of sodium excretion of women $(p<0.0001)$. Box-Whisker-Plots (Fig. 1) indicated different ranges of estimated daily sodium excretion-determined by the applied equations-in the German population (stratified by age groups). Interquartile ranges varied from 41-133 mmol (men) and 21-119 mmol (women). Using Brown's equation resulted in narrow distributions, whereas Johner's equation caused a broad distribution of estimated sodium excretion.

A sensitivity analysis assuming extreme low sodium concentrations $(1 \mathrm{mmol} / \mathrm{L})$ for values below the MQL of $20 \mathrm{mmol} / \mathrm{L}$ resulted in slightly lower mean estimates (mean values decreased by $0-4 \mathrm{mmol} / \mathrm{d}$ in men and by $0-9 \mathrm{mmol} / \mathrm{d}$ in women equivalent to $0-2 \%$ (men) and $0-5 \%$ (women) lower mean values).

\section{Comparison of daily sodium excretion with recommendations of daily sodium intake}

Figure 1 also highlights the relationship between estimated sodium excretion ranges and reference values suggested by the WHO [15], the nutrition societies of Germany, Austria, and Switzerland [19], IOM [2], and AHA [16]. For example, the WHO [15] recommends consuming less than $85 \mathrm{mmol}$ sodium per day, and most of the German population consume more than that regardless of the equation that is applied for extrapolation (Fig. 1, solid lines). The highest proportion of men (13\%) and women (19\%) consuming sodium as recommended by the WHO is seen with the equation originating from German people [28]. Having a set point of $100 \mathrm{mmol}$ (Fig. 1, dashed line), as discussed by others $[2,19]$, does not markedly change the figure.

\section{Correlation of results obtained with various equations}

The intraclass correlation (ICC, Table 4) between the results of the several equations was relatively high $($ ICC $>0.7$ ) among men (i.e., Brown-Tanaka, Kawasaki-Toft, KawasakiJohner, Tanaka-Toft) and to a lesser extent among women (i.e., Kawasaki-Tanaka, Kawasaki-Johner). A weak correlation (ICC <0.3) of the results was identified particularly among women (i.e., Brown-Kawasaki, Brown-Tanaka, Brown-Johner, Toft-Johner, Toft-Kawasaki) compared to men (i.e., Brown-Johner).

Creatinine is a crucial parameter in all equations. The estimation of daily creatinine excretion is part of Kawasaki's, Tanaka's, Toft's, and Johner's equation to calculate daily sodium excretion from spot urine concentrations. As 
Table 1 Comparison of study populations used to develop equations

\begin{tabular}{|c|c|c|c|c|c|}
\hline & $\begin{array}{l}\text { Johner et al. }(2014,2015) \\
{[28,36]}\end{array}$ & Toft et al. (2014) [31] & Brown et al. (2013) [35] & Tanaka et al. (2002) [32] & Kawasaki et al. (1993) [33] \\
\hline Study & VERA & DanThyr \& Inter99 & Intersalt & Intersalt & \\
\hline n & 1463 & 473 & 5693 & 591 & 159 \\
\hline Age (years) & $20-79$ & $25-65$ & $20-59$ & $20-59$ & $20-79$ \\
\hline Female (\%) & 58 & 78 & 50 & 50 & 51 \\
\hline Region & Germany & Denmark & North America \& Europe & Japan & Japan \\
\hline Spot urine sample & & Casual urine & Casual urine & Casual urine & Second morning urine \\
\hline $\begin{array}{l}\text { Mean Na concentration } \\
(\mathrm{mmol} / \mathrm{d})\end{array}$ & & 195 (men) 139 (women) & $147-240(\text { men })^{a} \quad 118-168$ (women) ${ }^{a}$ & 198 (men) 177 (women) & 233 (men) 186 (women) \\
\hline $\begin{array}{l}\text { Parameters considered to } \\
\text { estimate creatinine reference } \\
\text { values }\end{array}$ & Age group, sex & $\begin{array}{l}\text { Age, sex, body mass, body } \\
\text { height }\end{array}$ & & $\begin{array}{l}\text { Age, body mass, body } \\
\text { height }\end{array}$ & Age, sex, body mass, body height \\
\hline $\begin{array}{l}\text { Parameters considered to } \\
\text { estimate daily } \mathrm{Na} \text { excretion }\end{array}$ & $\begin{array}{l}\mathrm{Na} \text { concentration in casual } \\
\text { urine, creatinine } \\
\text { concentration in casual } \\
\text { urine, creatinine reference } \\
\text { value }\end{array}$ & $\begin{array}{l}\text { Na concentration in casual } \\
\text { urine, creatinine } \\
\text { concentration in casual urine, } \\
\text { creatinine reference value, } \\
\text { sex }\end{array}$ & $\begin{array}{l}\text { Na concentration in casual urine, } \\
\text { Creatinine concentration in casual } \\
\text { urine, sex, BMl, age (only women), K } \\
\text { concentration in casual urine }\end{array}$ & $\begin{array}{l}\mathrm{Na} \text { concentration in casual } \\
\text { urine, creatinine } \\
\text { concentration in casual } \\
\text { urine, creatinine reference } \\
\text { value }\end{array}$ & $\begin{array}{l}\text { Na concentration in second } \\
\text { morning urine, creatinine } \\
\text { concentration in second morning } \\
\text { urine, creatinine reference value }\end{array}$ \\
\hline
\end{tabular}

Key characteristics of study populations which were used to develop equations to estimate daily sodium excretion from spot urine concentrations (casual urine: sampling at any daytime possible, no time

me targeted)

${ }^{\text {a }}$ Range of the means of included regions 
Table 2 Characteristics of the DEGS1 study population

\begin{tabular}{|c|c|c|c|}
\hline & & Men (48 \%) & Women (52 \%) \\
\hline \multirow[t]{5}{*}{ Age (years) } & $18-29$ & $19.1 \%$ & $18.6 \%$ \\
\hline & $30-44$ & $25.9 \%$ & $24.4 \%$ \\
\hline & $45-64$ & $37.0 \%$ & $36.6 \%$ \\
\hline & $65-79$ & $18.0 \%$ & $20.4 \%$ \\
\hline & all & $100 \%(n=3312)$ & $100 \%(n=3598)$ \\
\hline \multirow[t]{5}{*}{$B M l^{a}$} & $<18.5$ & $0.7 \%$ & $2.4 \%$ \\
\hline & $18.5-<25$ & $32.2 \%$ & $45.1 \%$ \\
\hline & $25-<30$ & $43.9 \%$ & $29.0 \%$ \\
\hline & $>30$ & $23.2 \%$ & $23.5 \%$ \\
\hline & All & $100 \%(n=3312)$ & $100 \%(n=3598)$ \\
\hline \multirow{4}{*}{$\begin{array}{l}\text { Socio-economic } \\
\text { status }^{b, c}\end{array}$} & Low & $18.5 \%$ & $20.0 \%$ \\
\hline & Middle & $59.3 \%$ & $62.0 \%$ \\
\hline & High & $22.2 \%$ & $18.1 \%$ \\
\hline & All & $100 \%(n=3288)$ & $100 \%(n=3574)$ \\
\hline \multirow[t]{5}{*}{ Smoking ${ }^{c}$} & Daily & $26.1 \%$ & $21.7 \%$ \\
\hline & Sometimes & $6.5 \%$ & $5.7 \%$ \\
\hline & Formerly & $33.5 \%$ & $22.9 \%$ \\
\hline & Never & $34.0 \%$ & $49.7 \%$ \\
\hline & All & $100 \%(n=3293)$ & $100 \%(n=3576)$ \\
\hline \multirow[t]{5}{*}{ Exercise $^{c}$} & Never & $32.9 \%$ & $33.3 \%$ \\
\hline & $<2$ h per week & $38.0 \%$ & $44.7 \%$ \\
\hline & 2-4 h per week & $15.5 \%$ & $14.9 \%$ \\
\hline & $>4$ h per week & $13.5 \%$ & $7.1 \%$ \\
\hline & All & $100 \%(n=3213)$ & $100 \%(n=3509)$ \\
\hline \multirow[t]{4}{*}{ Cooking ${ }^{c, d}$} & Almost daily & $40.1 \%$ & $61.1 \%$ \\
\hline & $\begin{array}{l}1-4 \text { times per } \\
\text { week }\end{array}$ & $43.9 \%$ & $36.0 \%$ \\
\hline & Never & $16.0 \%$ & $2.9 \%$ \\
\hline & All & $100 \%(n=3227)$ & $100 \%(n=3531)$ \\
\hline
\end{tabular}

${ }^{\mathrm{a}} \mathrm{BMI}$ (body mass index) is calculated from body mass and body height ${ }^{\mathrm{b}}$ Socioeconomic status is assigned based on education, occupation, and income [30]

'Assessed via questionnaire

${ }^{\mathrm{d}}$ Frequency of preparation of a hot meal using basic/fresh ingredients by themselves expected, resulting mean estimated daily creatinine excretion data are comparable: $15.2-17.0 \mathrm{mmol} / \mathrm{d}$ (men) and $10.2-11.9 \mathrm{mmol} / \mathrm{d}$ (women). However, median values and the range of estimated creatinine values differ among applied equations (Fig. 2). The results obtained for men with the equations by Kawasaki, Tanaka, and Toft correlate reasonably well with each other (ICC >0.7, Table 5). In women, only creatinine values estimated with the equation by Toft and Kawasaki correlate well. Creatinine values as used in Johner's equation do not correlate well with estimates of either of the other equations ( $\mathrm{ICC}<0.3$, Table 5 ).

\section{Discussion}

High sodium intake has been claimed to be responsible for increased blood pressure and adverse cardiovascular effects [38]. WHO, AHA, IOM, and DGE recommend a reduction of sodium intake in populations [2, 15-17, 19]. Many countries developed and implemented salt reduction strategies [39]. However, Germany did not implement a salt reduction strategy up to now. One reason is the uncertainty about the actual sodium intake of the German population. We present representative, biomarker-based ranges of sodium excretion values of the German population. We also show the uncertainty of using spot urine to be extrapolated to daily excretion. However, regardless of the varying estimates of the sodium excretion in the German population, all of those estimates are far above the recommended sodium intake levels. Only a very small proportion of the population reach the WHO goal of consuming less than $85 \mathrm{mmol}$ sodium per day despite the fact that intake of too much sodium has been discussed for many years in public. However, our results are consistent with large studies investigating sodium intake around the world. In the PURE study comprising over 100,000 adults, the mean sodium excretion was $214 \mathrm{mmol}$ per day, and only $0.6 \%$ of the participants consume less than the $85 \mathrm{mmol}$ sodium per day [9]. Powles et al. [40] analyzed 245 surveys conducted around the world and classified the results by global regions. The mean sodium excretion has been estimated to be $172 \mathrm{mmol}$ per day with regional differences, and it did not meet the recommended limit of 85

Table 3 Average estimates of sodium intake

\begin{tabular}{|c|c|c|c|c|c|c|c|c|}
\hline & \multicolumn{4}{|l|}{ Men } & \multicolumn{4}{|l|}{ Women } \\
\hline & $\begin{array}{l}\text { Mean } \\
(\mathrm{mmol} / \mathrm{d})\end{array}$ & $\begin{array}{l}\text { Cl mean } \\
(\mathrm{mmol} / \mathrm{d})\end{array}$ & $\begin{array}{l}\text { Median } \\
(\mathrm{mmol} / \mathrm{d})\end{array}$ & $\begin{array}{l}\mathrm{Cl} \text { median } \\
(\mathrm{mmol} / \mathrm{d})\end{array}$ & $\begin{array}{l}\text { Mean } \\
(\mathrm{mmol} / \mathrm{d})\end{array}$ & $\begin{array}{l}\text { Cl mean } \\
(\mathrm{mmol} / \mathrm{d})\end{array}$ & $\begin{array}{l}\text { Median } \\
(\mathrm{mmol} / \mathrm{d})\end{array}$ & $\begin{array}{l}\text { Cl median } \\
(\mathrm{mmol} / \mathrm{d})\end{array}$ \\
\hline Johner $[28,36]$ & 194 & 188-199 & 174 & $168-180$ & 167 & $163-171$ & 149 & $144-154$ \\
\hline Toft [31] & 205 & $203-207$ & 206 & $204-208$ & 138 & 137-139 & 138 & 137-139 \\
\hline Brown [35] & 166 & $165-168$ & 164 & $162-166$ & 124 & $123-125$ & 123 & $122-124$ \\
\hline Tanaka [32] & 169 & $167-170$ & 168 & $166-170$ & 162 & $161-164$ & 160 & $158-162$ \\
\hline Kawasaki [33] & 230 & $226-233$ & 228 & $224-231$ & 194 & 192-196 & 190 & 187-193 \\
\hline
\end{tabular}

Mean and median daily sodium excretion of German men and women estimated with various methods 


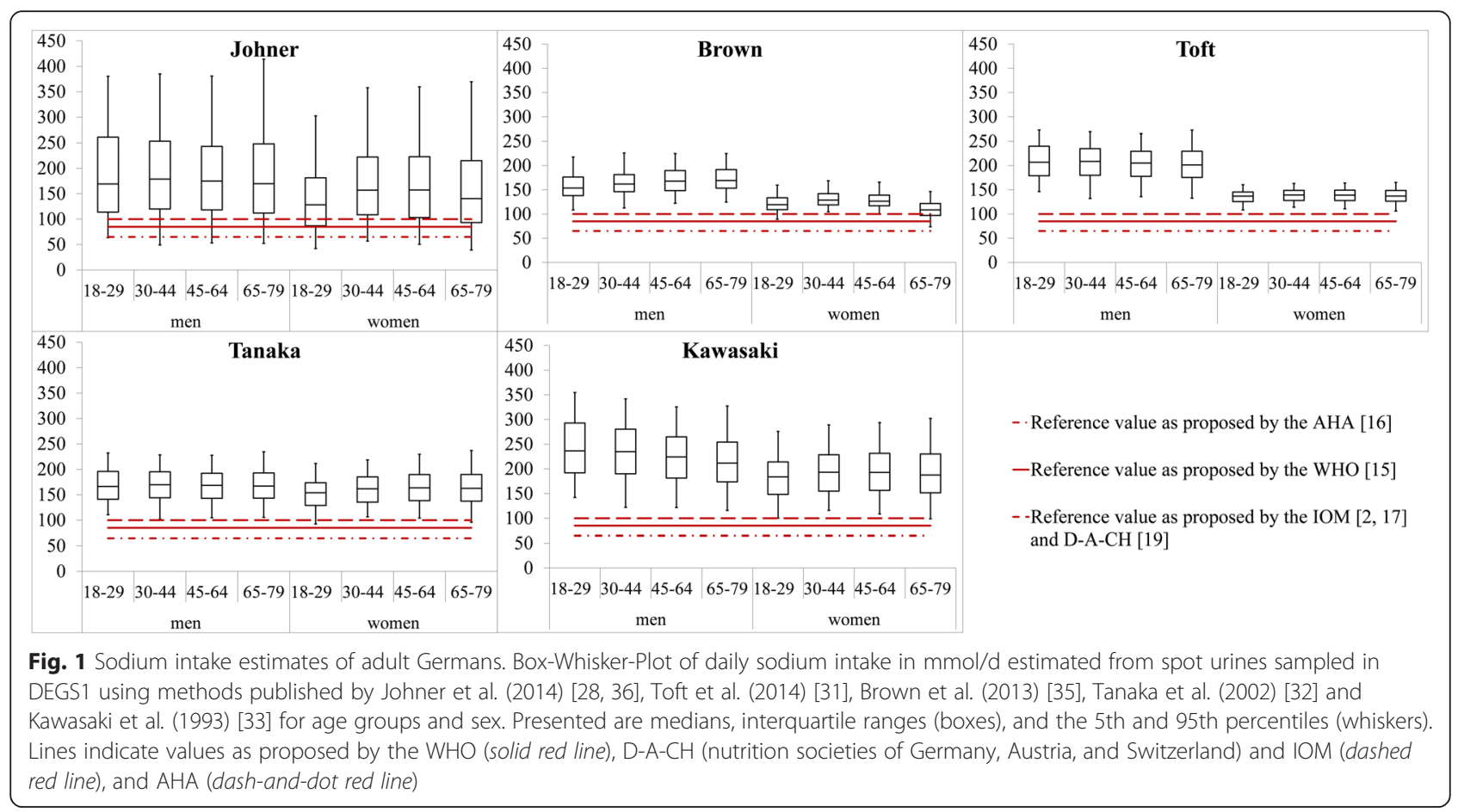

mmol per day in any region. Similarly, McCarron et al. [41] focused on studies that only used 24-h urine from 45 countries and estimated a mean daily sodium intake of $159 \mathrm{mmol}$. None of the 190 identified datasets had a mean sodium intake value below or even close to 85 mmol. Additionally, Brown et al. [42] found that most adult populations have mean sodium intakes of more than $100 \mathrm{mmol}$ per day. Women uniformly consume less sodium $[40,43,44]$ as a reflection of lower caloric intake with lower intake of nutrients [45].

Ensuing from general recommendations given by the WHO and other institutions, German men and women consume too much sodium, which is thought to negatively impact cardiovascular health. However, based on the recently observed association with mortality and cardiovascular events [10], there is still uncertainty about the optimal level of sodium intake. Alderman and Cohen [46] defined the common range of sodium intake associated with lower risk of cardiovascular events (109$261 \mathrm{mmol} / \mathrm{d}$ ) at a comparable range as that of O'Donnell et al. [10]. This result, however, should be taken with caution because no causality can be derived from such studies. They compare groups that consume different levels of sodium, but based on such studies it is not possible to argue that an intentional reduction of sodium intake would alter the risk of death or cardiovascular

Table 4 Correlation of sodium estimates obtained with various equations

\begin{tabular}{llllll}
\hline & Brown [35] & Kawasaki [33] & Tanaka [32] & Toft [31] & Johner [28] \\
\hline Brown [35] & - & 0.170 & 0.294 & 0.469 & 0.164 \\
Kawasaki [33] & 0.326 & $(-0.081-0.410)$ & $(-0.085-0.571)$ & $(0.084-0.679)$ & $(0.081-0.241)$ \\
& $(-0.076-0.598)$ & & 0.761 & 0.275 & 0.784 \\
Tanaka [32] & 0.717 & 0.542 & $(-0.045-0.922)$ & $(-0.090-0.557)$ & $(0.598-0.869)$ \\
& $(0.700-0.734)$ & $(-0.081-0.828)$ & & 0.519 & 0.623 \\
Toft [31] & 0.464 & 0.816 & 0.706 & $(-0.018-0.760)$ & $(0.603-0.643)$ \\
& $(-0.083-0.743)$ & $(0.414-0.917)$ & $(-0.007-0.922)$ & - & 0.275 \\
Johner [28] & 0.267 & 0.750 & 0.523 & 0.572 & $(0.203-0.341)$ \\
& $(0.220-0.311)$ & $(0.567-0.841)$ & $(0.456-0.581)$ & $(0.545-0.597)$ & - \\
\end{tabular}




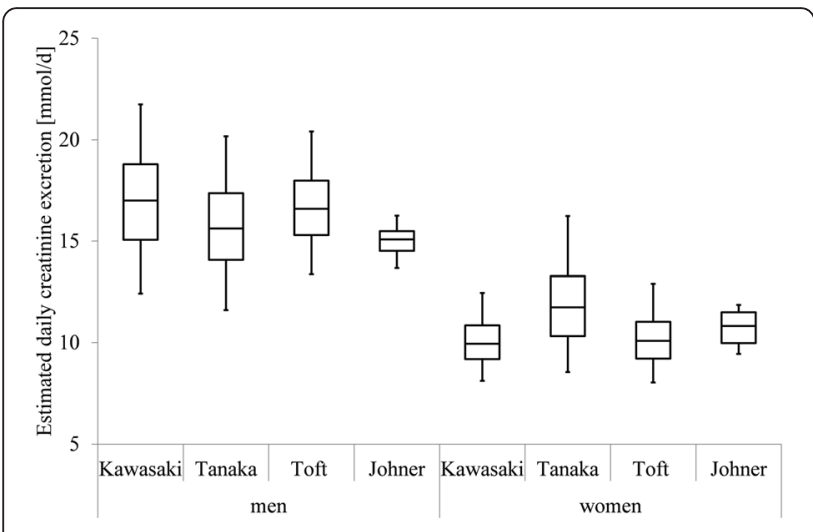

Fig. 2 Estimated creatinine excretion. Box-Whisker-Plot of estimated daily creatinine excretion in mmol/d using various methods [31-33, 36]. Presented are median and interquartile range (box) and the 5th and 95th percentile (whiskers)

health. McCarron et al. [41] concluded from such observations-among others-that the common sodium intake is not associated with negative health impacts.

A recent study analyzed sodium intake of 419 participants using 24-h urine collections (mean sodium excretion: $150 \mathrm{mmol} / \mathrm{d}$ ) and found no correlation with either knowledge of the impact of salt on health, beliefs whether they eat too much, the right amount or too little salt, or their behavior regarding salt consumption [47]. This outcome may partly explain why people still consume too much salt. A recent study, including 4680 individuals (40-59 years) from different populations [48] observed that only a few participants reported an attempt to reduce their salt intake with diet $(1-7 \%$ of participants, $15 \%$ of those with treated hypertension). Of those who did, the effect was only modest (reduction of $\sim 14 \mathrm{mmol}$ ), which might be explained by the observations by Land et al. [47]. Thus, sodium intake remained at levels that are much higher than recommended $(\sim 150-180 \mathrm{mmol} / \mathrm{d})$ even if people try to reduce it [48].
For a national survey such as DEGS that aims to collect much data of the participants and aims for high response rates, the gold standard for sodium intake estimation is not suitable. Countries that used 24-h urine collection in a nationally representative survey mostly reported low response rates [23]. Therefore, urine was collected only once in DEGS when participants visited the study center (casual spot urine). Some equations have been developed to extrapolate concentrations of sodium in casual spot urine to the excretion within $24 \mathrm{~h}$, which have been used and compared in the present study. The applied equations resulted in a range of estimated daily sodium excretion for men and women in Germany. It is likely that the actual daily sodium excretion in the adult German population is within the range of estimates of the applied equations. Unfortunately, the range of even average (mean, median) results is rather broad. The available information does not allow us to conclude the validity of any of these equations for the DEGS population because 24-h urine was not collected in the study population to validate the resulting estimates. However, there are some facts that are indicative for one or another equation; Johner's equation is derived from German adults at the age range of DEGS participants, but it does not account for body mass and height. Brown's equation is derived from the largest study population conducted in North America and Europe, and median results best fit with NVSII estimates [26, 27]. Kawasaki's equation is derived from a population that reflects the age range of DEGS participants, but it is based on the Japanese population and second morning urine samples (Table 1).

Several studies have evaluated the accuracy of some equations already by comparing extrapolated sodium excretion with measured 24-h urine collections [31, 32, 49-53]. The assessment revealed contradictory conclusions. Kawasaki's equation seems to overestimate sodium excretion by differing degree [49-51]. Whereas Cogswell et al. [49] found an average overestimation of more than

Table 5 Correlation of creatinine estimates obtained with various equations

\begin{tabular}{|c|c|c|c|c|c|}
\hline & Kawasaki [33] & Tanaka [32] & Toft [31] & Johner [36] & \\
\hline \multirow[t]{2}{*}{ Kawasaki [33] } & - & 0.533 & 0.984 & 0.268 & women \\
\hline & & $(-0.091-0.810)$ & $(0.970-0.990)$ & $(0.101-0.403)$ & \\
\hline \multirow[t]{2}{*}{ Tanaka [32] } & 0.813 & - & 0.570 & 0.083 & \\
\hline & $(0.623-0.891)$ & & $(-0.085-0.827)$ & $(0.034-0.130)$ & \\
\hline \multirow[t]{2}{*}{ Toft [31] } & 0.937 & 0.870 & - & 0.284 & \\
\hline & $(0.932-0.942)$ & $(0.588-0.940)$ & & $(0.165-0.386)$ & \\
\hline \multirow[t]{3}{*}{ Johner [36] } & 0.236 & 0.124 & 0.208 & - & \\
\hline & $(0.082-0.363)$ & $(0.086-0.161)$ & $(0.035-0.353)$ & & \\
\hline & men & & & & \\
\hline
\end{tabular}


$50 \mathrm{mmol} / \mathrm{d}$, Mente et al. [50] concluded that the estimates with Kawasaki's equation were the least biased. Brown's equation, in contrast, seems to underestimate daily sodium excretion by a differing degree [49-51]. Cogswell et al. [49] concluded that results obtained with Brown's equation are least biased. Using Tanaka's equation resulted in over- and underestimation of measured daily sodium excretion in various evaluation studies [31, 32, 49-53]. Particularly, sodium excretion of women seems to be overestimated with Tanaka's equation [31, 49, 52], and sodium excretion of men is probably underestimated [31]. Two studies found results with Toft's equation to correlate better with 24-h urine samples compared with Tanaka's equation $[31,52]$. The precision of estimates seems to be influenced by the level of sodium intake [51,53], as well as the time of spot urine sampling $[24,49,53]$.

The timing of spot urine sampling could indeed partly explain deviating results. Some evaluation studies [50,51] used one timed spot urine sample (first morning or fasting morning urine samples, respectively). In DEGS and three equation development studies [31, 32, 35], however, casual spot urine samples (which are not collected at a specific time) were used. Diurnal rhythm of sodium excretion, with a low sodium excretion rate in the morning and higher sodium excretion rate in the afternoon, has been demonstrated [54-57]. The circadian rhythm is independent of meals, activities and sodium content of the meals [57]. The acrophase is between 15:00 and 16:00 [56], and the amplitude of the circadian rhythm is approximately $25 \%$ [57] or $50 \%$ to $60 \%$ [56], respectively. This diurnal rhythm is expressed in lower estimated daily sodium excretion based on morning spot urines and higher estimated daily sodium excretion based on afternoon spot urines [53]. Thus, Kawasaki et al. (1993) developed their equation based on generally lower sodium concentrations in morning urine samples. In comparison, other researchers included the diurnal variability of sodium concentrations by using casual urine samples (in common with DEGS samples). Therefore, it can be suspected that estimated daily sodium excretion using Kawasaki's equation likely overestimates sodium intake of the German population. The impact of timing of the urine samples is even more complicated in considering the dipping status of hypertensives. Normally, blood pressure falls at night (dipper) which is accompanied by lower sodium excretion [58]. In some people, blood pressure does not fall at night (non-dipper), and this lack of change seems to be associated with an increased nocturnal sodium excretion that blunts or even reverses the circadian rhythm of sodium excretion. The dipping status is also associated with the level of sodium intake and might also be related to salt sensitivity [58].
There is agreement that extrapolation of the sodium concentration in spot urines to the daily sodium excretion with the applied equations is inadequate for the estimation of an individual's sodium intake [32, 51]. The equations were developed to estimate the population mean of sodium excretion from spot urine collections for comparing various groups, populations and annual trends as stated by Tanaka et al. [32]. We found that even in this approach, the available methods are potentially misleading for the stated reasons and reflected by the presented results. Consistent with this idea, Ji et al. [59] concluded that methods based on spot urines to estimate sodium intake in populations are likely to produce biased results and are not reproducible. However, other assume that spot urine samples extrapolated with Browns equation result in a reasonable estimate of key population indicators [22]. However, the need for more reliable alternatives to the 24-h urine collection to monitor sodium intake level in populations has been noted several times [22, 23, 60, 61].

Although 24-h urine sampling is considered the goldstandard to assess sodium intake, it also comprises some limitations that are valid for the use of spot urine samples too. First, people do not eat the same foods in the same amounts every day. Hence, an intra-individual day-to-day variance of sodium intake should be assumed. The magnitude of this variance depends on individual habits, and it is difficult to estimate on a population level. Based on two 24-h urine samples of 133 Americans, Wang et al. [62] expected the within-person-variability of sodium excretion to be $23 \%$ (black people) and $19 \%$ (other races).

Second, to assess the sodium intake within a day, the complete intake of sodium should be analyzed. This assessment is possible by a duplicate diet study, but it is a costly approach and very burdensome for participants. Alternatively, the sodium excretion in urine within $24 \mathrm{~h}$ can be analyzed. This approach is easier to implement and it is believed that sodium in 24-h urine is a good measure of intake presuming a balance of sodium intake and urinary sodium excretion. Indeed, sodium excretion in sweat $(\sim 3 \mathrm{mmol} / \mathrm{d})$ and feces $(\sim 3-4 \mathrm{mmol} / \mathrm{d})$ can be neglected under normal conditions [63]. However, sodium intake and excretion seems to not always be balanced [63]. At high sodium intake $(400 \mathrm{mmol} / \mathrm{d}$ and more), significantly less sodium is excreted in urine, which results in a positive sodium balance. In contrast, at low sodium intake levels $(\sim 50 \mathrm{mmol} / \mathrm{d})$, significantly more sodium is excreted in urine (negative sodium balance) - at least on the first day of the intervention. However, sodium intake equals urinary excretion at a sodium intake level that is supposed to be normal $(\sim 200 \mathrm{mmol} / \mathrm{d})$ [63]. The notion that 24-h urine sampling is the gold standard to measure daily sodium intake [61] is further challenged by the observation that the variability of daily 
sodium excretion is not only determined by the variation of consumption habits as mentioned before. Rakova et al. [64] found that sodium excretion was subject to a weekly rhythm in a highly controlled study at defined sodium intake levels $(103,154$, and $205 \mathrm{mmol}$ ) over at least 29 days per level. This marked variability in urinary sodium excretion at a constant sodium intake seems to be endocrinedriven. The Mars flight simulation data confirmed the steady-state-concept of sodium - within a time frame of weeks, but not within one day [64]. The agreement between one single carefully collected 24-h urine and the corresponding recorded daily sodium intake (103 - 205 mmol sodium per day) are not sufficient to detect 50mmol differences in individual sodium intake [65]. The identified rather low precision in assessing sodium intake on a daily basis is consequently also present when daily sodium excretion is extrapolated from spot urine concentrations. This means that the predictive value of one single 24-h urine (measured or extrapolated) to classify individual sodium intake is low. However, assessing the average sodium intake in populations is probably not biased by this finding because equal deviations from the predicted sodium intake in either direction are present [65]. The detection of the storage and accumulation of sodium in different tissues like skin provides an explanation where sodium is retained and released during the observed rhythm of excretion [66].

\section{Conclusions}

In the first representative investigation of sodium intake of adults in Germany measured by sodium excretion, much higher intake levels were identified for most of the population as recommended by the WHO and other institutions (irrespective of the applied equation). The available equations to extrapolate sodium excretion from spot urine to $24 \mathrm{~h}$ result in different mean estimates as well as variable intake ranges. The resulting estimates are likely biased. Therefore, better methods to estimate sodium intake on a population level need to be applied. This estimation could be either by implementing costlier investigations (such as 24-h urine collection on population level) or to refine the extrapolation when using casual spot urine samples. The latter should include the derivation of an equation based on the investigated population using 24-h urines of a representative subpopulation. It should consider the timing of urine sampling to account for the circadian rhythm of sodium excretion. Such an extrapolation should also consider ethnicity and comprise the entire range of sodium excretion, in addition to sex, age, body mass and body height and creatinine excretion. The adjustment of the dipping status of hypertensive people, which affects the circadian rhythm of sodium excretion, is important but difficult to assess in population-based studies.

\section{Abbreviations}

AHA, American Heart Association; Al, adequate intake; BMI, Body Mass Index; DEGS1, German Health Interview and Examination Survey for Adults; DGE, Deutsche Gesellschaft für Ernährung, German Nutrition Society; EFSA, European Food Safety Authority; ICC, Intraclass Correlation Coefficient; IOM, Institute of Medicine; MQL, Method Quantification Limit; NVSII, Nationale Verzehrsstudie II, German National Nutrition Survey II; ÖGE, Österreichische Gesellschaft für Ernährung, Austrian Nutrition Society; SGE, Schweizerische Gesellschaft für Ernährung, Swiss Nutrition Society; UI, Tolerable Upper Intake Level; WHO, World Health Organization

\section{Acknowledgements}

Not applicable.

Funding

DEGS1 is funded by the German Ministry of Health (BMG).

\section{Availability of data and materials}

DEGS data are available as public use file at RKI homepage (http:// www.rki.de/DE/Content/Gesundheitsmonitoring/PublicUseFiles/ informationen_datensaetze/info_datensaetze_node.html).

\section{Authors' contributions}

SK planed and performed data analysis, drafted and revised the manuscript. MT is responsible for the measurement of urine samples and revised the manuscript. MT and GM were involved in the design and conduct of DEGS1. GM contributed to data analysis and revised the manuscript. All authors read and approved the final manuscript.

\section{Authors' information}

Not applicable.

\section{Competing interests}

The authors declare that they have no competing interests.

Consent for publication

Not applicable.

Ethics approval and consent to participate

The DEGS1 study protocol was consented with the Federal and State Commissioners for Data Protection and approved by the CharitéUniversitätsmedizin Berlin ethics committee in September 2008 (No. EA2/ 047/08). Informed consent was obtained from all participants.

Received: 27 November 2015 Accepted: 4 June 2016

Published online: 13 June 2016

\section{References}

1. Trinquart L, Johns DM, Galea S. Why do we think we know what we know? A metaknowledge analysis of the salt controversy. Int J Epidemiol. 2016;45(1):251-60. doi:10.1093/ije/dyv184.

2. IOM, Institute of Medicine. Sodium Intake in Populations: Assessment of Evidence. Washington, DC: The National Acadamies Press; 2013.

3. He FJ, Li J, Macgregor GA. Effect of longer term modest salt reduction on blood pressure: Cochrane systematic review and meta-analysis of randomised trials. BMJ. 2013;346:f1325. doi:10.1136/bmj.f1325.

4. Hooper L, Bartlett C, Davey Smith G, Ebrahim S. Systematic review of long term effects of advice to reduce dietary salt in adults. BMJ. 2002;325(7365): 628. doi:10.1136/bmj.325.7365.628.

5. Strazzullo P, D'Elia L, Kandala NB, Cappuccio FP. Salt intake, stroke, and cardiovascular disease: meta-analysis of prospective studies. BMJ. 2009;339: b4567. doi:10.1136/bmj.b4567.

6. He FJ, MacGregor GA. Salt reduction lowers cardiovascular risk: metaanalysis of outcome trials. Lancet. 2011;378(9789):380-2. doi:10.1016/s01406736(11)61174-4.

7. Taylor RS, Ashton KE, Moxham T, Hooper L, Ebrahim S. Reduced dietary salt for the prevention of cardiovascular disease: a meta-analysis of randomized controlled trials (Cochrane review). Am J Hypertens. 2011;24(8):843-53. doi:10.1038/ajh.2011.115.

8. Graudal NA, Hubeck-Graudal T, Jurgens G. Effects of low-sodium diet vs. high-sodium diet on blood pressure, renin, aldosterone, catecholamines, 
cholesterol, and triglyceride (Cochrane Review). Am J Hypertens. 2012;25(1): 1-15. doi:10.1038/ajh.2011.210.

9. Mente A, O'Donnell MJ, Rangarajan S, McQueen MJ, Poirier P, Wielgosz A, et al. Association of urinary sodium and potassium excretion with blood pressure. N Engl J Med. 2014;371(7):601-11. doi:10.1056/NEJMoa1311989.

10. O'Donnell M, Mente A, Rangarajan S, McQueen MJ, Wang X, Liu L, et al. Urinary sodium and potassium excretion, mortality, and cardiovascular events. N Engl J Med. 2014;371(7):612-23. doi:10.1056/NEJMoa1311889.

11. Dickinson KM, Clifton PM, Keogh JB. A reduction of $3 \mathrm{~g} /$ day from a usual $9 \mathrm{~g} /$ day salt diet improves endothelial function and decreases endothelin-1 in a randomised cross_over study in normotensive overweight and obese subjects. Atherosclerosis. 2014;233(1):32-8. doi: 10.1016/j.atherosclerosis.2013.11.078.

12. Kopp C, Linz P, Dahlmann A, Hammon M, Jantsch J, Muller DN, et al. 23Na magnetic resonance imaging-determined tissue sodium in healthy subjects and hypertensive patients. Hypertension. 2013;61(3):635-40. doi:10.1161/ HYPERTENSIONAHA.111.00566.

13. Cappuccio FP. Cardiovascular and other effects of salt consumption. Kidney Int Suppl (2011). 2013;3(4):312-5. doi:10.1038/kisup.2013.65.

14. Jantsch J, Schatz V, Friedrich D, Schroder A, Kopp C, Siegert I, et al. Cutaneous na(+) storage strengthens the antimicrobial barrier function of the skin and boosts macrophage-driven host defense. Cell Metab. 2015;21(3):493-501. doi:10.1016/j.cmet.2015.02.003.

15. WHO, World Health Organization. Guideline: Sodium Intake for Adults and Children. Geneva, CH: WHO; 2012

16. Appel LJ, Frohlich ED, Hall JE, Pearson TA, Sacco RL, Seals DR, et al. The importance of population-wide sodium reduction as a means to prevent cardiovascular disease and stroke: a call to action from the American Heart Association. Circulation. 2011;123(10):1138-43. doi:10.1161/CIR. 0b013e31820d0793.

17. IOM, Institute of Medicine. Dietary Reference Intakes for Water, Potassium, Sodium, Chloride, and Sulfate. Washington, DC: The National Academies Press; 2005.

18. EFSA, European Food Safety Authority. Opinion of the Scientific Panel on Dietetic Products, Nutrition and Allergies on a request from the Commission related to the Tolerable Upper Intake Level of Sodium. The EFSA Journal. 2005;3(6):1-26. doi:10.2903/j.efsa.2005.209.

19. DGE ÖGE, SGE. D-A-CH Referenzwerte für die Nährstoffzufuhr. 1st ed. Bonn: DGE, ÖGE, SGE; 2015

20. Elliott P, Brown I. Sodium intake around the world - Background document prepared for the Forum and Technical meeting on Reducing Salt Intake in Populations (Paris 5-7th October 2006). Geneva: World Health Organization; 2007.

21. Bentley B. A review of methods to measure dietary sodium intake. J Cardiovasc Nurs. 2006;21(1):63-7.

22. McLean RM. Measuring population sodium intake: a review of methods. Nutrients. 2014:6(11):4651-62. doi:10.3390/nu6114651.

23. Hawkes $C$, Webster J. National approaches to monitoring population salt intake: a trade-off between accuracy and practicality? PLoS One. 2012;7(10): e46727. doi:10.1371/journal.pone.0046727.

24. Mann SJ, Gerber LM. Estimation of 24-hour sodium excretion from spot urine samples. J Clin Hypertens (Greenwich). 2010;12(3):174-80. doi:10.1111/ j.1751-7176.2009.00241.x.

25. BfR, Bundesinstitut für Risikobewertung. Blutdrucksenkung durch weniger Salz in Lebensmitteln. Stellungnahme Nr. 007/2012 des BfR, MRI und RKI vom 19. Oktober 2011. Berlin, DE: Bundesinstitut für Risikobewertung, MRI, Max-Rubner-Institut; RKI, Robert-Koch-Institut; 2011. Report No.: 007/2012.

26. MRI, Max Rubner-Institut, Bundesforschungsinstitut für Ernährung und Lebensmittel. Nationale Verzehrsstudie II - Die bundesweite Befragung zur Ernährung von Jugendlichen und Erwachsenen: Ergebnisbericht Teil 2. Karlsruhe, DE: Max Rubner-Institut; 2008.

27. Hartmann BM, Grotz A, Stang K, Heuer T, Hoffmann I. Die aktuelle Version 3. 01 des Bundeslebensmittelschlüssels (BLS): Neuerungen und Auswirkungen. Proceedings of the German Nutrition Society 2011.

28. Johner SA, Thamm M, Schmitz R, Remer T. Current daily salt intake in Germany: biomarker-based analysis of the representative DEGS study. Eur J Nutr. 2014. doi:10.1007/s00394-014-0787-8.

29. Scheidt-Nave C, Kamtsiuris P, Gosswald A, Holling H, Lange M, Busch MA, et al. German health interview and examination survey for adults (DEGS) - design, objectives and implementation of the first data collection wave. BMC Public Health. 2012;12:730. doi:10.1186/1471-2458-12-730.
30. Lampert T, Kroll L, Muters S, Stolzenberg H. Measurement of socioeconomic status in the German Health Interview and Examination Survey for Adults (DEGS1). Bundesgesundheitsblatt Gesundheitsforschung Gesundheitsschutz. 2013:56(5-6):631-6. doi:10.1007/s00103-012-1663-4.

31. Toft U, Cerqueira C, Andreasen AH, Thuesen BH, Laurberg P, Ovesen L, et al. Estimating salt intake in a Caucasian population: can spot urine substitute 24-hour urine samples? Eur J Prev Cardiol. 2014;21(10):1300-7. doi:10.1177/ 2047487313485517.

32. Tanaka T, Okamura T, Miura K, Kadowaki T, Ueshima H, Nakagawa H, et al. A simple method to estimate populational 24-h urinary sodium and potassium excretion using a casual urine specimen. J Hum Hypertens. 2002;16(2):97-103. doi:10.1038/s/j/jh/1001307.

33. Kawasaki T, Itoh K, Uezono K, Sasaki H. A simple method for estimating $24 \mathrm{~h}$ urinary sodium and potassium excretion from second morning voiding urine specimen in adults. Clin Exp Pharmacol Physiol. 1993;20(1):7-14. doi:10.1111/j.1440-1681.1993.tb01496.x.

34. Kawasaki T, Uezono K, Itoh K, Ueno M. Prediction of 24-hour urinary creatinine excretion from age, body weight and height of an individual and its application. Nihon Koshu Eisei Zasshi. 1991;38(8):567-74.

35. Brown IJ, Dyer AR, Chan Q, Cogswell ME, Ueshima H, Stamler J, et al. Estimating 24-hour urinary sodium excretion from casual urinary sodium concentrations in Western populations: the INTERSALT study. Am J Epidemiol. 2013;177(11):1180-92. doi:10.1093/aje/kwt066.

36. Johner SA, Boeing H, Thamm M, Remer T. Urinary 24-h creatinine excretion in adults and its use as a simple tool for the estimation of daily urinary analyte excretion from analyte/creatinine ratios in populations. Eur J Clin Nutr. 2015. doi:10.1038/ejen.2015.121.

37. Kamtsiuris $P$, Lange $M$, Hoffmann R, Schaffrath Rosario A, Dahm S, Kuhnert $R$, et al. The first wave of the German Health Interview and Examination Survey for Adults (DEGS1): sample design, response, weighting and representativeness. Bundesgesundheitsblatt Gesundheitsforschung Gesundheitsschutz. 2013;56(5-6):620-30. doi:10.1007/s00103-012-1650-9.

38. Whelton PK, Appel $\amalg$, Sacco RL, Anderson CA, Antman EM, Campbell N, et al. Sodium, blood pressure, and cardiovascular disease: further evidence supporting the American Heart Association sodium reduction recommendations. Circulation. 2012;126(24):2880-9. doi:10.1161/CIR.0b013e318279acbf.

39. Trieu K, Neal B, Hawkes C, Dunford E, Campbell N, Rodriguez-Fernandez R, et al. Salt Reduction Initiatives around the World - A Systematic Review of Progress towards the Global Target. PLoS One. 2015;10(7):e0130247. doi:10.1371/journal.pone.0130247.

40. Powles J, Fahimi S, Micha R, Khatibzadeh S, Shi P, Ezzati M, et al. Global, regional and national sodium intakes in 1990 and 2010: a systematic analysis of $24 \mathrm{~h}$ urinary sodium excretion and dietary surveys worldwide. BMJ Open. 2013;3(12):e003733. doi:10.1136/bmjopen-2013-003733.

41. McCarron DA, Kazaks AG, Geerling JC, Stern JS, Graudal NA. Normal range of human dietary sodium intake: a perspective based on 24-hour urinary sodium excretion worldwide. Am J Hypertens. 2013;26(10):1218-23. doi:10.1093/ajh/hpt139.

42. Brown IJ, Tzoulaki I, Candeias V, Elliott P. Salt intakes around the world: implications for public health. Int J Epidemiol. 2009;38(3):791-813. doi:10.1093/ije/dyp139.

43. Bernstein AM, Willett WC. Trends in 24-h urinary sodium excretion in the United States, 1957-2003: a systematic review. Am J Clin Nutr. 2010;92(5): 1172-80. doi:10.3945/ajcn.2010.29367.

44. Beer-Borst S, Costanza MC, Pechere-Bertschi A, Morabia A. Twelve-year trends and correlates of dietary salt intakes for the general adult population of Geneva, Switzerland. Eur J Clin Nutr. 2009;63(2):155-64. doi:10.1038/sj. ejcn.1602922.

45. De Keyzer W, Dofkova M, Lillegaard IT, De Maeyer M, Andersen LF, Ruprich $J$, et al. Reporting accuracy of population dietary sodium intake using duplicate $24 \mathrm{~h}$ dietary recalls and a salt questionnaire. Br J Nutr. 2015;113(3): 488-97. doi:10.1017/50007114514003791.

46. Alderman $\mathrm{MH}$, Cohen HW. Dietary sodium intake and cardiovascular mortality: controversy resolved? Curr Hypertens Rep. 2012;14(3):193-201. doi:10.1007/s11906-012-0275-6.

47. Land MA, Webster J, Christoforou A, Johnson C, Trevena H, Hodgins F, et al. The association of knowledge, attitudes and behaviours related to salt with 24-hour urinary sodium excretion. Int J Behav Nutr Phys Act. 2014;11(1):47. doi:10.1186/1479-5868-11-47.

48. Okuda N, Stamler J, Brown IJ, Ueshima H, Miura K, Okayama A, et al. Individual efforts to reduce salt intake in China, Japan, UK, USA: what did 
people achieve? The INTERMAP Population Study. J Hypertens. 2014;32(12): 2385-92. doi:10.1097/HJH.0000000000000341.

49. Cogswell ME, Wang CY, Chen TC, Pfeiffer CM, Elliott P, Gillespie CD, et al. Validity of predictive equations for 24-h urinary sodium excretion in adults aged 18-39 y. Am J Clin Nutr. 2013;98(6):1502-13. doi:10.3945/ajcn.113. 059436.

50. Mente A, O'Donnell MJ, Dagenais G, Wielgosz A, Lear SA, McQueen MJ, et al. Validation and comparison of three formulae to estimate sodium and potassium excretion from a single morning fasting urine compared to 24-h measures in 11 countries. J Hypertens. 2014;32(5):1005-14. doi:10.1097/HJH. 0000000000000122 . discussion 15.

51. Rhee MY, Kim JH, Shin SJ, Gu N, Nah DY, Hong KS, et al. Estimation of 24hour urinary sodium excretion using spot urine samples. Nutrients. 2014;6(6):2360-75. doi:10.3390/nu6062360.

52. Hooft van Huysduynen EJ, Hulshof PJ, van Lee L, Geelen A, Feskens EJ, van 't Veer $\mathrm{P}$, et al. Evaluation of using spot urine to replace $24 \mathrm{~h}$ urine sodium and potassium excretions. Public Health Nutr. 2014;17(11):2505-11. doi:10.1017/S1368980014001177.

53. Kawamura M, Ohmoto A, Hashimoto T, Yagami F, Owada M, Sugawara T. Second morning urine method is superior to the casual urine method for estimating daily salt intake in patients with hypertension. Hypertens Res. 2012:35(6):611-6. doi:10.1038/hr.2012.6.

54. Kawasaki T, Nakamuta S, Fukiyama K, Omae T. Determination of urinary excretion of aldosterone and sodium by short term collections of urine in healthy men. Jpn Circ J. 1979;43:621-6. doi:10.1253/jjj.43.621.

55. Kawasaki T, Uezono K, Ueno M, Omae T, Matsuoka M, Haus E, et al. Comparison of circadian rhythms of the renin-angiotensin-aldosterone system and electrolytes in clinically healthy young women in Fukuoka (Japan) and Minnesota (USA). Acta Endocrinol (Copenh). 1983;102(2):246-51. doi:10.1530/acta.0.1020246

56. Muratani H, Kawasaki T, Ueno M, Kawazoe N, Fujishima M. Circadian rhythms of urinary excretions of water and electrolytes in patients receiving total parenteral nutrition (TPN). Life Sci. 1985;37:645-9. doi:10.1016/00243205(85)90431-X.

57. Wesson Jr LG, Lauler DP. Diurnal cycle of glomerular filtration rate and sodium and chloride excretion during responses to altered salt and water balance in man. J Clin Invest. 1961:40:1967-77. doi:10.1172/JCl104422.

58. Sachdeva A, Weder AB. Nocturnal sodium excretion, blood pressure dipping, and sodium sensitivity. Hypertension. 2006;48(4):527-33. doi:10.1161/01.HYP.0000240268.37379.7c.

59. Ji C, Miller MA, Venezia A, Strazzullo P, Cappuccio FP. Comparisons of spot vs $24-h$ urine samples for estimating population salt intake: validation study in two independent samples of adults in Britain and Italy. Nutr Metab Cardiovasc Dis. 2014;24(2):140-7. doi:10.1016/j.numecd.2013.06.011.

60. WHO/PAHO, World Health Organization/Pan American Health Organization Regional Expert Group for Cardiovascular Disease Prevention through Population-wide Dietary Salt Reduction. Protocol for population level sodium determination in 24-hour urine samples. Geneva: WHO; 2010.

61. Ji C, Sykes L, Paul C, Dary O, Legetic B, Campbell NR, et al. Systematic review of studies comparing 24-hour and spot urine collections for estimating population salt intake. Rev Panam Salud Publica. 2012;32(4):30715. doi:10.1590/S1020-49892012001000010.

62. Wang CY, Cogswell ME, Loria CM, Chen TC, Pfeiffer CM, Swanson CA, et al. Urinary excretion of sodium, potassium, and chloride, but not iodine, varies by timing of collection in a 24-hour calibration study. J Nutr. 2013;143(8): 1276-82. doi:10.3945/jn.113.175927.

63. Heer M, Baisch F, Kropp J, Gerzer R, Drummer C. High dietary sodium chloride consumption may not induce body fluid retention in humans. Am J Physiol Renal Physiol. 2000;278(4):F585-95.

64. Rakova N, Juttner K, Dahlmann A, Schroder A, Linz P, Kopp C, et al. Longterm space flight simulation reveals infradian rhythmicity in human $\mathrm{Na}(+)$ balance. Cell Metab. 2013;17(1):125-31. doi:10.1016/j.cmet.2012.11.013.

65. Lerchl K, Rakova N, Dahlmann A, Rauh M, Goller U, Basner M, et al. Agreement between 24-hour salt ingestion and sodium excretion in a controlled environment. Hypertension. 2015;66(4):850-7. doi:10.1161/ HYPERTENSIONAHA.115.05851.

66. Titze J. Sodium balance is not just a renal affair. Curr Opin Nephrol Hypertens. 2014;23(2):101-5. doi:10.1097/01.mnh.0000441151.55320.c3.

\section{Submit your next manuscript to BioMed Central and we will help you at every step:}

- We accept pre-submission inquiries

- Our selector tool helps you to find the most relevant journal

- We provide round the clock customer support

- Convenient online submission

- Thorough peer review

- Inclusion in PubMed and all major indexing services

- Maximum visibility for your research

Submit your manuscript at www.biomedcentral.com/submit
() BioMed Central 